DOI: $10.5216 /$ rs.v5.55525

\title{
O ENSINO DE LÍNGUA PORTUGUESA PARA ALUNOS SURDOS: PRÁTICAS DE ALFABETIZAÇÃO E LETRAMENTO
}

PORTUGUESE LANGUAGE FOR DEAF STUDENTS: LITERACY PRACTICES

\author{
Antonio Wadan Gomes Cavalcante* \\ Cibelle Eurídice Araújo Torres **
}

\begin{abstract}
Resumo
O presente artigo objetiva perceber como acontece o ensino de língua portuguesa - LP para alunos surdos e se estes estão imbuídos em práticas sociais do letramento ou de alfabetização. Para sua efetivação foi realizado uma pesquisa com abordagem qualitativa e estudo de caso, em que o trabalho se consolidou através de observações na escola José Freire Filho - Crateús - CE nas salas inclusivas pesquisadas nesta escola. Este estudo apoiou-se nos escritos de Soares, Kleiman, Botelho, Fernandes e outros, para expor que alunos surdos não são alfabetizados em língua de sinais e, mesmo desconhecendo sua língua natural, são expostos ao ensino de Língua Portuguesa - LP. Ao final deste trabalho, percebe-se a necessidade de uma reforma na educação de alunos surdos, com vistas a rever as práticas metodológicas de ensino e ofertar, de forma isonômica, um ensino pautado nas especificidades do aluno.
\end{abstract}

Palavras-chave: Alfabetização. Letramento. Libras. Língua portuguesa.

\section{Introdução}

Esta pesquisa aborda o ensino de língua portuguesa para alunos surdos em uma escola do município de Crateús, Ceará. O interesse em pesquisar esse assunto emergiu a partir de questões envolvendo a educação inclusiva que abordavam como os sujeitos surdos são alfabetizados concomitantemente em língua portuguesa e libras, a que chamaremos aqui de L2 e L1, respectivamente. As discussões acerca do ensino e aprendizagem de alunos surdos sempre foram alvo de debates por parte de pesquisadores da área. A década de 1990 inaugura essas

\footnotetext{
*Instituto Federal de Educação, Ciência e Tecnologia do Ceará (IFCE), Crateús, Ceará, Brasil. E-mail: antonio.cavalcante4@prof.ce.gov.br

${ }^{* *}$ Instituto Federal de Educação, Ciência e Tecnologia do Ceará (IFCE), Crateús, Ceará, Brasil. E-mail: cibelle.araujo@ifce.edu.br
} 
discussões, já aguçadas no que diz respeito aos alunos surdos. Nessa década foram iniciados debates sobre a educação de surdos, o bilinguismo, a Língua Brasileira de Sinais e a cultura surda. Tiveram como protagonistas destes movimentos os próprios surdos, familiares e professores engajados em causas inclusivas e outros grupos que buscavam espaço social.

Com efeito, estas manifestações conclamavam também por uma Lei que ratificasse e assegurasse o direito de inclusão do aluno surdo em escolas. A LDB - Lei de Diretrizes e Bases da Educação Nacional, em seu artigo $24^{\circ}$ do decreto Lei 3.298/99 postula que, "a pessoa com deficiência tem direito à educação pública e gratuita, preferencialmente, na rede regular de ensino e, ainda, à educação adaptada às suas necessidades educacionais especiais" (BRASIL, 1996). Portanto, para efeito de cumprimento dessa Lei, as escolas de ensino regular, estão obrigadas a receberem matrícula de alunos com deficiência, seja motora, visual, auditiva ou qualquer outra.

Esta pesquisa busca compreender como acontece o ensino de língua portuguesa para alunos surdos em uma escola de Crateús, Ceará, e ainda, de forma mais específica, a alfabetização de alunos surdos nessas aulas, ou seja, como eles aprendem a ler, a escrever, e se estão ou não sendo inseridos em práticas sociais de letramento.

A Libras, de acordo com Monteiro (2006), não era concebida, dentro das comunidades de ouvintes, como uma língua natural e materna da pessoa com surdez, tampouco recebia o status de língua, mas, por força de Leis e Decretos, como a Lei de no 10.436, a Libras fora oficializada no Brasil como a língua de aquisição primária da pessoa surda. Desde então, ela começou a exercer papel fundamental na alfabetização de estudantes surdos, tendo em vista a sua necessidade de apreensão primária, como L1, pois, é praticamente impossível alfabetizar um aluno surdo sem que ele conheça primeiro a organização linguística da sua língua de berço.

Talvez esse seja o principal problema a ser enfrentado tanto pela escola quanto pelos alunos. A carência de profissionais especializados para trabalharem com estas peculiaridades do ensino, a barreira criada por muitos professores que se sentem incapazes de incluir um aluno com deficiência pela falta de formação, a ausência de recursos pedagógicos adaptados e necessários para a construção de um ensino comprometido com a formação do discente surdo, o preconceito arraigado dos próprios familiares e da sociedade de que essas pessoas não conseguem desenvolver habilidades de leitura e escrita, e, até mesmo, a não aceitação da identidade surda pelo surdo, são alguns dos fatores que contribuem de forma significativa para a exclusão dessas pessoas. Quadros (2005, p.6) afirma que: 
Quando a criança surda tiver a chance de, no início do seu desenvolvimento, contar com pais dispostos a aprender a língua de sinais, com adultos surdos, com colegas surdos, quando ela narrar em sinais e tiver escuta em sinais, a dimensão do seu processo educacional será outra.

Muitos professores que trabalham com alunos surdos desconhecem, ou acabam por deixar de lado, o fato de que a Libras obedece a um compêndio de regras que regulam a comunicação entre os usuários, assim como o português, ou qualquer outra língua. Da mesma forma, a Libras também apresenta todos os níveis de análise de uma língua convencional. Quadros e Karnopp (2004), em seus estudos sobre a Libras, apontam que, em 1960, Stokoe, estudioso da ASL - Língua Americana de Sinais, concebeu que a língua de sinais atende a todo os requisitos linguísticos de uma língua genuína, com a capacidade de construir números infinitos de unidades dotadas de sentido.

O ensino de Libras nas escolas está tomando dimensões mais acentuadas e chegando não só a alunos usuários dela, como também, fazendo parte do repertório idiomático de alunos ouvintes. Podemos considerar um grande avanço na educação, pois, até meados dos anos 2000, os próprios alunos surdos que não foram alfabetizados ou letrados em sua língua de berço, não tinham acesso preponderante a ela (FERNANDES, 2006).

O uso da língua de sinais é uma característica identitária de grande importância. Os surdos, organizados em comunidades, consideram o uso da língua de sinais uma evidência de pertença à comunidade surda. "A língua é uma atividade em evolução, assim o é a identidade" (SÁ, 2002, p. 130).

A língua de sinais é uma das principais identidades da pessoa surda. Mas nós, ouvintes, também somos convocados a conhecer, pelo menos, o básico da Libras, pois assim estaremos contribuindo para a inclusão da pessoa surda nos diversos contextos de interação. Muitas vezes, dedicamos tanto do nosso tempo para aprender uma língua distante da nossa realidade de profissional docente, que deixamos de lado uma língua genuinamente brasileira, sem contar que nos deparamos diariamente com pessoas, alunos, amigos surdos e que precisam, de certa forma, manter uma comunicação mínima, seja com o seu professor, com o atendente da farmácia, do comércio ou em uma consulta médica.

Com isso, levo em consideração também a legitimidade que a Libras tem tomado no sistema de ensino. Apesar de ser novidade no currículo de muitas escolas, sua implantação é 
necessária, embora ainda haja resistência por parte dos professores, alunos, coordenação e toda estrutura organizacional. Talvez esse seja o entrave, resultante de não se produzir conhecimentos linguísticos acerca da língua, como se produz no português. Com isso o ensino da Libras se reduz à apresentação repetitiva de sinais para a memorização e, consequentemente, o estudante não consegue desenvolver uma aprendizagem satisfatória da língua.

Albres (2003) enfatiza que as dificuldades de leitura e escrita são fatores resultantes da ausência de métodos e procedimentos de ensino adequados para discentes surdos. Afirma ainda, que a proposta de uma educação bilíngue no Brasil está se acentuando para a formação de alunos surdos monolíngues, com conhecimentos satisfatórios sobre a Libras e escasso domínio em leitura e escrita da língua portuguesa.

Diante desse quadro, pretendeu-se realizar uma pesquisa com abordagem qualitativa e estudo de caso, por meio de observações. Utilizamo-nos também da pesquisa de caráter bibliográfico, com o objetivo de reunir e identificar os problemas enfrentados na educação de surdos no sistema regular de ensino, exclusivamente. Por este viés, são poucas as pesquisas relacionadas à alfabetização ou ao letramento de alunos com surdez, no ensino de língua portuguesa.

No levantamento bibliográfico feito para a composição deste trabalho, buscou-se as produções científicas de três professoras universitárias, duas da UFMG e uma da Unicamp, além de outras referências citadas ao longo do trabalho. Botelho (2013) traz concepções acirradas e críticas ferrenhas sobre o nosso desconhecimento em relação à língua do surdo. Suas inquietações são justificadas pelos resultados escolares de alunos surdos e o fracasso de alguns professores, no que tange às metodologias de ensino para alunos surdos. A pesquisa realizada por Botelho (2013), sobre linguagem, letramento, ensino e aprendizagem de alunos surdos, foi o pilar onde se ancorou este estudo.

Esta pesquisa se deu através de um estudo de caso de natureza descritiva com abordagem qualitativa. Primeiramente, procuramos à Secretaria Municipal de Educação de Crateús/CE, em que fizemos um mapeamento acerca das escolas que tinham alunos surdos matriculados, dentre elas, escolas da zona rural e urbana. Feito o mapeamento, nos detivemos apenas a uma escola municipal da sede, localizada no bairro 2000 que atende três alunos surdos, todos eles são acompanhados por intérpretes em todos os componentes curriculares.

Como procedimento de geração de dados, utilizamos observações com registro em diário de campo, realizadas na Escola de Cidadania José Freire Filho no município de Crateús 
(CE) e acompanhamos a aulas de LP de dois professores de língua portuguesa, como também, dois intérpretes dos $6^{\circ}$ e $7^{\circ}$ anos da escola supracitada, em cujo contexto escolar consta a presença do intérprete educacional. As observações totalizaram cerca de vinte encontros na escola. Nas observações das aulas de língua portuguesa, priorizamos aspectos relacionados ao ensino de língua portuguesa para alunos com surdez, assim como, procuramos também entender se as práticas metodológicas de ensino dos professores de língua majoritária, estão voltadas para a formação de um aluno letrado e alfabetizado em L2.

\section{O que é a Libras?}

A Libras é uma língua oficial brasileira e há leis que asseguram às comunidades surdas o seu uso e também o seu ensino. A Lei 10.436 (BRASIL, 2002), que dispõe sobre a Língua Brasileira de Sinais, em seu artigo $1^{\circ}$ afirma que:

É reconhecida como meio legal de comunicação e expressão a Língua Brasileira de Sinais - Libras e outros recursos de expressão a ela associados. Parágrafo único. Entende-se como Língua Brasileira de Sinais - Libras, a forma de comunicação e expressão, em que o sistema linguístico de natureza visual-motora, com estrutura gramatical própria, constitui um sistema linguístico de transmissão de ideias e fatos, oriundos de comunidades de pessoas surdas do Brasil.

O decreto Lei de número 5.626 (BRASIL, 2005), que chancela a Lei supracitada, afirma em seu Artigo $2^{\circ}$ :

Para os fins deste Decreto, considera-se pessoa surda aquela que, por ter perda auditiva, compreende e interage com o mundo por meio de experiências visuais, manifestando sua cultura principalmente pelo uso da Língua Brasileira de Sinais - Libras. Parágrafo único. Considera-se deficiência auditiva a perda bilateral, parcial ou total, de quarenta e um decibéis $(\mathrm{dB})$ ou mais, aferida por audiograma nas frequências de $500 \mathrm{~Hz}, 1.000 \mathrm{~Hz}, 2.000 \mathrm{~Hz}$ e $3.000 \mathrm{~Hz}$

A Libras, sendo uma língua de sinais, também contempla os níveis linguísticos encontrados no português, tais como: fonológico, morfológico, sintático e semântico. O que a diferencia das demais línguas, é a sua modalidade de comunicação, pois por se tratar de sinais, a Libras dispõe da modalidade visual-espacial, enquanto nas línguas oral-auditivas é a palavra que assume esta posição. 


\section{A aquisição da língua portuguesa na educação bilíngue por alunos surdos}

O ensino da tecnologia da escrita em língua portuguesa para alunos surdos, tem sido um dilema constante entre os professores desses estudantes. A principal alegação apresentada pelos educadores é o despreparo das escolas, das salas e dos professores para recepcionarem esses alunos. Outro ponto que traz graves problemas à educação de surdos, é o material didático ofertado pela escola. De acordo com Lima (2007), em uma pesquisa realizada com 8 professores que atendem alunos com surdez, $90 \%$ destes profissionais, indagaram que enfrentam a mesma problemática, o material de apoio oferecido pela instituição não dá suporte didático aos docentes, tampouco aos discentes.

Aos poucos, a educação de surdos tem tomado novos contornos a partir de abordagens metodológicas mais atuais de ensino. Por muito tempo, a educação de surdos presenciou metodologias de ensino que estavam voltadas para o ensino da modalidade oral da língua, ou seja, o objetivo era ensinar o surdo a falar, porém não obtiveram resultados satisfatórios e tampouco o surdo tinha desenvolvimento linguístico. Nesse período, como já mencionado anteriormente, os alunos deveriam aprender as regras da língua falada, para se socializarem com os ouvintes. No ensino da Língua Portuguesa predominava, nessa época, a concepção de língua como código, ou seja, como um conjunto de regras que os alunos deveriam aprender para entendê-la e usá-la bem (PEREIRA, 2014).

A nova concepção de metodologia que se configura no atual contexto de ensino, redesenha as práticas pedagógicas tornando os alunos mais ativos no processo de aprendizagem, não mais deixando de lado sua língua e sua cultura, mas tendo como pressuposto básico, a concepção de que só podemos partir para o ensino de língua portuguesa escrita quando este aluno estiver totalmente letrado e alfabetizado em sua língua materna.

Com a aprovação do Decreto Federal n ${ }^{\circ}$ 5.626, de 22 de dezembro de 2005, que decretou, entre outras atribuições, o ensino bilíngue, o surdo teve mais acesso a sua língua. De acordo com a Lei, ele deve ser primeiramente exposto à sua língua de berço e, logo após, de forma secundária, à língua oficial do seu país. A proposta da educação bilíngue no Brasil, inaugura um grande marco para a comunidade surda, que durante muito tempo, foi amordaçada por questões políticas e religiosas. Souza (1998) assinala que o bilinguismo, por oferecer o ensino das duas línguas, requer uma posição política do Estado, que dê suporte a esse grupo minoritário de usuários. 
Neste tópico, pretende-se apresentar o bilinguismo como a metodologia mais adequada para aquisição de L1 e L2 na educação dos surdos. Embora o bilinguismo seja, atualmente, bem aceito, há questões que ainda precisam ser debatidas e solucionadas. De acordo com Lima (2014, p. 2-3), os profissionais e a comunidade surda reconhecem haver, de alguma forma,

[...] desvantagem escolar desses indivíduos, sendo comum a presença de surdos nas séries iniciais, com uns oito anos de vida escolar, sem uma produção escrita compatível com seu grau de escolaridade. Pesquisas indicam que um número elevado de sujeitos surdos apresenta competências acadêmicas muito aquém do desempenho de alunos ouvintes, apesar de suas capacidades cognitivas serem semelhantes.

Com efeito, é importante lembrarmos de que nem todo surdo fluente em língua de sinais tem um bom desenvolvimento em língua portuguesa. As dificuldades em assimilar uma língua se dão por vários motivos, um deles, que podemos destacar neste estudo, é o ambiente familiar. Muitas vezes, há alunos surdos filhos de pais ouvintes que não são usuários da Libras. O único contato desse aluno com a sua língua será no ambiente escolar, ao passo que muitos deles chegam à escola sem nenhuma língua constituída (PEREIRA, 2014).

Um questionamento que tem gerado dúvidas aos pesquisadores da área é se a aquisição de L2 é próxima, na concepção de aprendizagem do aluno surdo, à aquisição de L1, em termos de metodologia. Lillo-Martin (1998) ressalta que aprendizes de L2 angariam conceitos, a grosso modo, da gramática universal, incluindo os princípios que não foram fixados na aquisição da língua materna. Na concepção de Lima (2014, p. 6), outros pesquisadores argumentam que:

[...] os princípios da GU não estão disponíveis aos aprendizes adultos da L2. Segundo essa hipótese, quanto mais tarde se adquire uma segunda língua, especialmente após a adolescência, menos chance há de se marcar os parâmetros da GU que não foram fixados e estavam disponíveis no processo de aquisição da primeira língua.

Dessa forma, a aprendizagem de L2 pelos alunos surdos só será possível, sendo essa uma língua oral, se o estudante tiver acesso ao código escrito. Contudo, o acesso à escrita de outra língua, deve acontecer o quanto antes, pois quanto mais cedo o surdo tiver contato com as duas línguas de forma concomitante, mais cedo será a aquisição de uma e outra. Svartholm (2003) sugere que esses estudantes sejam expostos, ainda na educação infantil, a diferentes gêneros textuais, como tirinhas, anúncios e, principalmente, histórias em quadrinhos, pois esses 
textos, além de entreter, ajudam o aluno a manter sintonia com a língua, por meio de textos imagéticos.

Aos professores, cabe a reprodução dos textos em Libras. A contação de histórias se dá a partir do tripé: texto, imagem e sinal. À medida que o professor expõe as ações da história que está sendo contada, ele deve apresentar o sinal que representa aquela palavra e, $\operatorname{logo}$ em seguida, a forma escrita em língua portuguesa. Em consonância com as orientações curriculares, numa educação bilíngue, "a Língua Portuguesa é considerada a segunda língua dos alunos surdos, o que significa que seu aprendizado vai se basear nas habilidades linguísticas adquiridas na Língua Brasileira de Sinais" (PEREIRA, 2008, pg.22).

Esses pressupostos estão ancorados em ideias defendidas por SOARES (2017), BOTELHO (2013) e FERNANDES (2003) pensamentos já defendidos pelos estudiosos que se interessam por este campo de estudos. Para que uma pessoa ouvinte aprenda uma segunda língua é necessário que, primeiro, ela conheça os aspectos linguísticos de sua língua materna. Da mesma forma acontece com os surdos. Quanto mais cedo expostos à educação bilíngue, ao contato com pessoas surdas e ouvintes, mais fácil será aprender outra língua.

Quadros e Karnopp (2004), também ratificam, em seus escritos, que a língua de sinais é uma língua natural, adquirida de forma espontânea, e que a língua oral deve ser ensinada de forma sistematizada, tendo em vista que a língua materna será ensinada e adquirida no dia a dia, em contato com outras pessoas surdas, assim como acontece com os ouvintes.

A metodologia de ensino empregada na maioria das escolas públicas do Brasil, que trabalham com alunos surdos, se baseia no tripé didático-metodológico do texto, da imagem e do sinal, como exposto anteriormente. Na prática de alfabetização e letramento, o professor mostra a imagem ao aluno e, em seguida, apresenta o sinal referente àquela imagem. Por fim, mostra o texto, a palavra, em língua portuguesa para o aluno.

\section{Aporte teórico}

Os debates acerca da inclusão escolar da pessoa com deficiência, sempre geraram discussões que, muitas vezes, não saem do papel. Cada deficiência demanda uma proposta de metodologia de ensino diferente e as ações não poderiam ser homogêneas, principalmente quando falamos de uma prática de ensino voltada para pessoas que são atendidas pelo AEE (Atendimento Educacional Especializado). Cada estudante necessita de atendimento específico 
que supra suas necessidades de aprendizagem e, nesse contexto, vamos nos ater às práticas de alfabetização e letramento de alunos com surdez.

Quando nos referimos às práticas de alfabetização e letramento de alunos surdos, em língua portuguesa, estamos falando da aquisição do código escrito e das habilidades de Leitura e escrita. Nessa perspectiva, o indivíduo não só assimila o alfabeto como algo mecânico, em que o aluno codifica e decodifica, mas assume outras habilidades, como: a capacidade de interpretação, linguagem, compreensão, criticidade, produção, e as diversas formas de uso da língua nos mais variados contextos. De acordo com Brito (2015), a Leitura, a compreensão e a produção, numa relação de contexto social, são três eixos, bases para que a alfabetização e o letramento entrem em cena, no que tange ao ensino de L2 para alunos surdos. Portanto, iremos abordar os conceitos de alfabetização e letramento numa relação com o ensino de alunos surdos.

\subsection{O conceito de letramento}

Soares (2006) diz que alfabetizar é orientar o aprendiz para o domínio da tecnologia da escrita nos múltiplos contextos, enquanto letrar é conceder-lhe mecanismos para que seja capaz de fazer uso, nas práticas sociais, da leitura e da escrita. De acordo com esses conceitos, o estudante que sabe ler e escrever é uma pessoa alfabetizada e o que, além de saber ler e escrever, conhece os gêneros textuais e discursivos adequados a cada contexto social e faz uso deles, é uma pessoa letrada. A aquisição da leitura e da escrita, começa com o conhecimento das primeiras letras, antes mesmo de a criança ir à escola. Para Freire (2006), a leitura do mundo precede a leitura da palavra, e a leitura de mundo influencia o aluno a reconhecer, com mais facilidade, a leitura da palavra, da frase e do texto, consequentemente.

Em 1980, chegou ao Brasil a palavra "letramento", que surgiu no mesmo período em outros países como França, Portugal, Estados Unidos e Inglaterra. Soares (2017) observa que, no Brasil, o termo "letramento" é confundido, ou mesclado, com "alfabetização". De acordo com Soares (2017, p. 33), o "enraizamento do conceito de letramento no conceito de alfabetização pode ser detectado tomando-se para análise fontes como os sensos demográficos, a mídia, a produção acadêmica". Soares (2017, p. 35-36) completa, afirmando que "a invenção do letramento, entre nós, se deu por caminhos diferentes daqueles que explicam a invenção do termo em outros países, como a França e os Estados Unidos".

Assim, as práticas de ensino de línguas em sala de aula, são atravessadas por essa contenda travada na agregação do conceito de letramento e alfabetização. Numa visão holística 
da palavra letramentos, neste momento, tem-se em mente o contexto social como meio de aplicação dos conhecimentos advindos, ou adquiridos, da alfabetização, numa relação dinâmica. E foi considerando esse contexto, que buscamos entender se os alunos com surdez da escola José Freire Filho, em Crateús, estão sendo letrados, alfabetizados ou se os dois processos ocorrem de forma concomitante.

O letramento, em linhas gerais, busca a inserção do aluno em práticas sociais de leitura e escrita. Quanto ao ensino de educandos surdos e as multidefinições do termo "letramentos", podemos destacar o letramento visual como método de aquisição da língua para os surdos, tendo em vista sua língua materna ser a visual-espacial. Nesse sentido, além de desenvolver as habilidades de ler e escrever, o estudante deverá ter a habilidade de se apropriar da informação visual e entender o que está sendo exposto através de uma imagem, a do semáforo, por exemplo. (SILVINO, 2012). O processo de letramento desse aluno se desenvolve com base em três eixos, que vão ao encontro do ensino bilíngue: a palavra em L2, a imagem e o sinal.

A palavra "letramento" ainda é novidade no nosso vocabulário, embora tenha sido referenciada por Mary Kato, em 1986, e depois, em 1988, ter aparecido no livro que, segundo observa Soares (2017, p. 35),

[...] pode-se dizer que lançou a palavra no mundo da educação, e dedica páginas à definição de letramento e busca distinguir letramento de alfabetização: é o livro Adultos não alfabetizados: o avesso do avesso, de Leda Verdiani Tfouni, um estudo sobre o modo de falar e de pensar de adultos analfabetos.

Contudo, embora a terminologia ainda seja nova em nossa língua e nos estudos acerca da linguagem, a ocorrência da "mistura" entre letramento e alfabetização se dá, justamente, por serem práticas comuns e muito parecidas dentro do ambiente escolar onde, na maioria das vezes, acaba sendo difícil distinguir qual o papel do alfabetização e do letramento. Neste capítulo procuramos trazer algumas definições de "letramento". Kleiman (1995), define letramento como um conjunto de práticas sociais que usa a escrita como sistema simbólico e como tecnologia, em contextos específicos, para objetivos específicos. Sendo assim, o letramento pode ser compreendido como um leque de teorias que farão parte do repertório linguístico social do estudante, na comunidade de fala, nos mais diversos contextos de comunicação.

No caso do letramento de alunos surdos, tanto em língua natural, a Libras, quanto na língua majoritária do país, as práticas de letramento devem levar em conta a diferença entre os 
indivíduos, o canal de comunicação, mas não como sujeitos inferiores, incapazes de aprender. Brito (2015) defende que o surdo deve ser alfabetizado e letrado ao mesmo tempo, levando-se em conta os diversos contextos nos quais as práticas sociais da língua escrita acontecem para pessoas com necessidades auditivas especiais. O que deve ter maior destaque nos processos de ensino é o desenvolvimento cognitivo, linguístico e sociocultural, o que contribuirá para uma aprendizagem significativa do estudante surdo.

Portanto, os problemas tradicionais apontados como característicos da pessoa surda são produzidos por condições sociais. Não há limitações cognitivas ou afetivas inerentes à surdez, tudo depende das possibilidades oferecidas pelo grupo social para seu desenvolvimento, em especial para a consolidação da linguagem (apud GÖES, 1999, p.38).

De acordo com Botelho (2013), "letramento" é o estado daquele que não apenas sabe ler e escrever, mas que faz uso com propriedade da leitura e da escrita, mudando assim a sua visão do que está posto na sociedade. O aluno passa, portanto, de um sujeito passivo no uso da língua para um usuário competente. No que tange o letramento de alunos surdos, de acordo com a visão de Botelho, a escolarização não está voltada para a construção de sujeitos letrados. O que de fato permeia nas escolas é a edificação de um sujeito monolíngue. Privilegia-se a interação do surdo com os ouvintes, deixando de lado as concepções de letramento que deveriam fazer parte do ensino desses alunos. O contexto da escola inclusiva, muitas vezes, não contribui para o desenvolvimento linguístico de um sujeito letrado, pelo fato de a língua oral ser a de predominância naquele contexto.

Fernandes (2003) traz outro conceito de letramento, referindo-se a uma pesquisa aplicada no estado do Paraná, com alunos surdos. Para essa autora, letramento seria a aquisição da língua e a imersão nas práticas sociais de leitura e escrita. Fernandes compreende que a prática escolar está enveredando por um caminho profícuo para a educação dos surdos, quanto à aquisição de L2. Para ela, a alfabetização não deve ser pensada nos moldes tradicionais, mas em outros moldes adequados às necessidades dos surdos, pois o aluno surdo não aprenderá uma segunda língua a partir de processos vazios de sentidos para eles, como, por exemplo, o som de cada letra, que é um dos pressupostos da alfabetização.

\subsection{O conceito de alfabetização}

Nos últimos anos, tem-se atribuído definições inadequadas ao termo "alfabetização". Diferentes conceitos de alfabetização têm surgido desde a introdução do conceito de 
"letramento" no Brasil e nas escolas. Não se trata de dar valor e atestar credibilidade a uma prática, deletando outra do campo educacional. O que se objetiva é definir a alfabetização de acordo com sua prática no contexto escolar, tentando pôr em ordem a heterogeneidade de conceitos chumbados no termo, ratificando a importância de se trabalhar a alfabetização letrando, pois, ao mesmo tempo em que o sujeito é alfabetizado ele também é letrado nas práticas sociais. Atribuir acepções esparsas ao termo, seria negar-lhe a sua função prioritária, que é ensinar o código escrito e as habilidades de ler e escrever.

A alfabetização tem por finalidade ensinar às crianças o código alfabético, sem objetivo de formar um sujeito crítico e capaz de lutar pelos seus direitos.

Uma pessoa alfabetizada conhece o código alfabético, domina as relações grafônicas, em outras palavras, sabe que sons as letras representam, é capaz de ler palavras e textos simples, mas não necessariamente é usuário da leitura e da escrita na vida social (CARVALHO, 2010, p.66).

Por isso a necessidade de se alfabetizar letrando, pois esse processo vai além de codificar e decodificar o código. Para que a escola forme um ser pensante, crítico e ativo na sociedade, é necessário inseri-lo em situações que lhe permita experienciar a rotina social, os contextos sociais dos quais ele faz parte. Aqui, entra em palco o letramento. Em relação aos alunos surdos, a alfabetização oferece de forma parcial suporte para que adquiram uma segunda língua (L2). Devemos levar em conta o fato de que esse aluno jamais terá propriedade da representação fônica do código, apenas gráfica, por isso parcial. Como bem mencionou Fernandes (2003) em seus estudos, o letramento é uma das vertentes que mais se aproxima de uma metodologia adequada de ensino de L2 para os surdos, não puramente o letramento, mas ele é quem deve chefiar as relações embricadas no contexto escolar dos estudantes com surdez.

A alfabetização tradicional não dá conta das necessidades do alunado brasileiro, nem leva em conta as especificidades de cada estudante (aqui me refiro a alunos ouvintes e surdos). Sempre que nos deparamos com tais conceitos, percebemos a presença de duas instâncias mediadoras das práticas pedagógicas, a alfabetização e o letramento. O surdo deverá ser alfabetizado e letrado em L2 levando em consideração apenas a modalidade escrita da língua, enquanto que para os ouvintes além da escrita também a oralidade deve fazer parte deste processo, Soares (2017). Angariando estes pressupostos para a educação dos surdos, percebemos que os conceitos apresentados sobre alfabetização e letramento ainda carecem de 
aprimoramento para melhor tangenciar a educação de surdos. Outro conceito de alfabetização é postulado por Val (2006, p. 19), que define alfabetização como um processo:

[...] específico e indispensável de apropriação do sistema de escrita, a conquista dos princípios alfabético e ortográfico que possibilitem ao aluno ler e escrever com autonomia. Noutras palavras, alfabetização diz respeito à compreensão e ao domínio do chamado "código" escrito, que se organiza em torno de relações entre a pauta sonora da fala e as letras (e outras convenções) usadas para representá-la, a pauta, na escrita.

O conceito apresentado por Val não abarca todas as relações dialógicas construídas na escola, nem as relações de cunho linguístico, quer dizer, não envolve as várias linguagens existentes no contexto escolar, deixando de lado, mais uma vez, alunos com surdez, que não se apropriam da pauta sonora das convenções alfabéticas. Não se pretende lançar críticas à alfabetização e sepultá-la, nem singularizar o letramento, esquecendo do domínio do código escrito da língua. $\mathrm{O}$ que se pretende discutir neste estudo, são as vertentes mais adequadas à educação de surdos.

Em Perez (2002), encontramos uma definição que comunga com os preceitos adotados pelo letramento no que tange à aquisição da leitura e da escrita. De acordo com Perez (2002, p. 66), o processo de alfabetização e letramento:

[...] ainda que se inicie formalmente na escola, começa de fato, antes de a criança chegar à escola, através das diversas Leituras que vai fazendo do mundo que a cerca, desde o momento em que nasce e, apesar de se consolidar nas quatro primeiras séries, continua pela vida afora. Este processo continua apesar da escola, fora da escola paralelamente à escola.

Nessa perspectiva, é possível constatar que a alfabetização não se dá apenas no ambiente escolar, com um professor mediando reflexões, ela acontece antes, durante e depois da vida escolar, não se restringindo apenas a esse espaço de trocas e compartilhamentos, de saberes e relações. A alfabetização está intrinsecamente conectada às ideologias do letramento, por isso a necessidade de se alfabetizar letrando, duas práticas impossíveis de serem segregadas, mas que não são sinônimo. Alfabetizar é formar um sujeito capaz de ler e escrever, não apenas um bilhete simples, como mencionado em pesquisas por amostragem divulgadas pela UNESCO, mas ser capaz de ler o mundo a sua volta e entendê-lo, ser capaz de escrever a própria vida. A 
alfabetização pressupõe contato com a realidade e busca formar indivíduos aptos nas habilidades da língua, ou pelo menos em duas delas, ler e escrever.

Ferreiro e Teberosky (1999) ao investigarem as habilidades adquiridas de ler e escrever, às quais chama lecto-escrita, perceberam que as crianças em fase inicial de alfabetização, ou nível pré-silábico, edificam situações de escrita antes mesmo de ter propriedade sobre ela. Constroem conhecimentos mesmo desconhecendo o código. Isso se dá pelo fato de, antes mesmo de serem alfabetizadas, terem contato com o mundo externo à escola, contato diário com diversos gêneros discursivos, que contribuem para a formação de um sujeito letrado ainda na alfabetização.

\section{As filosofias educacionais e a surdez}

Nesta seção, apresentaremos as filosofias educacionais voltadas para o ensino de surdos, que balizaram as propostas de educação, gerando novos modelos de ensino para alunos surdos. As principais delas, que destaco neste trabalho, são: o oralismo, a comunicação total e o bilinguismo.

Durante os séculos, tem-se pensado em uma gama de abordagens e métodos de educação da pessoa surda. Quase sempre, a maioria das abordagens propõem a substituição da audição por um canal de comunicação sensorial, que facilite a comunicação, como por exemplo: o tato, a visão ou até resíduos auditivos.

Os estudos acerca das filosofias educacionais abordam ainda a questão dos métodos mais adequados para desenvolver a fala do surdo, Lacerda (1998) explica que as abordagens ou fases da educação de surdos tinham um único objetivo que era o de herança das famílias que possuíam grandes fortunas pois, geralmente, só poderia herdar quem pudesse se comunicar, logo, o surdo estava incapacitado de receber a herança dos pais e, por isso, precisava aprender a falar. Dessa forma, começou o desenvolvimento de métodos, técnicas e abordagens de ensinar o surdo a falar.

Com efeito, a educação de alunos com surdez passou por três fases durante o processo histórico de ensino. Cada um desses processos, ou filosofias, estavam vinculados aos desejos políticos, ou seja, a educação era rotulada de acordo com o pensamento dominante. De acordo com Goldified (2002) durante a Antiguidade e por quase toda a Idade Média o pensamento de que a pessoa surda não poderia ser educada fez com que por muitos anos o direito à educação 
fosse negado a esses sujeitos e tidos como incapazes de aprender um sistema linguístico e de se comunicarem.

\subsection{O oralismo}

O oralismo, metodologia de ensino aprovada no Congresso de Milão em 1880, foi uma filosofia que veio contradizer a cultura e a vida das pessoas surdas. Ensinar o surdo a falar era o principal objetivo desta metodologia. De acordo com seus defensores, essa seria a forma mais adequada para desenvolver nas crianças surdas a comunicação oral, tendo em vista que estavam em processo de aquisição da língua. Para Goldfeld (2002), este método se enquadra no modelo clínico-terapêutico e considera a importância da introdução do surdo na comunidade de ouvintes. Para Goldfeld (2002, p.34), o Oralismo,

[...] percebe a surdez como uma deficiência que deve ser minimizada pela estimulação auditiva. Essa estimulação possibilitaria a aprendizagem da língua portuguesa e levaria a criança surda a integrar-se na comunidade ouvinte e desenvolver uma personalidade como a de um ouvinte. Ou seja, o objetivo do oralismo é fazer uma reabilitação da criança surda em direção à normalidade.

Após o congresso de Milão, o conceito de surdez tomou outras configurações, com a implantação do modelo de reabilitação da fala. Sob a ótica oralista, os surdos eram tidos como deficientes. Um dos principais influenciadores deste método, que se mostrou ineficaz, foi o médico Alexander Graham Bell, que defendia a ideia de o surdo ser alguém que necessitava de tratamento para se curar. Além disso, Bell foi quem desenvolveu o telefone, a partir de um experimento realizado com o objetivo de reproduzir o aparelho fonador, que parecia ser um instrumento capaz de contribuir para comunicação dos surdos. Por mais de um século o oralismo sobrepujou as metodologias de ensino nas escolas de alunos surdos, nas residências e em locais públicos. Capovilla (2002, p.102), ao discorrer sobre tema, ressalta que o método oralista, nas escolas, "objetivava levar o surdo a falar e a desenvolver a competência linguística oral, o que lhe permitiria desenvolver-se emocional, social e cognitivamente do modo mais normal possível, integrando-se como um membro produtivo do mundo dos ouvintes".

Como afirma Dorziat (1997), com o método oralista introduzido nas escolas, era necessário o desenvolvimento de técnicas para que os surdos aprendessem a falar de forma 
rápida. Dentre as técnicas utilizadas pelos professores ouvintes, destacam-se as seguintes: o treinamento auditivo, o desenvolvimento da fala e a Leitura labial.

Com a epifania de novos estudos acerca da educação dos surdos, foi-se percebendo que o método de aquisição da fala, aprovado no Congresso de Milão, era falho e deixava muito a desejar, pois a persistência do uso da língua de sinais ainda era constante entre os surdos. Então, nesse período, iniciou-se a introdução de um novo modelo metodológico na educação dos alunos surdos, chamado "comunicação total”.

\subsection{A comunicação total}

A comunicação total surgiu em meados dos anos 60, nos Estados Unidos e estava caminhando a passos largos para aquilo que chamamos hoje de educação bilíngue. Em razão da filosofia oralista ter sido falha nas escolas, a comunicação total emergiu de forma interina, ou seja, os surdos podia se apropriar da língua de sinais somente como meio de comunicação, mas não seria a língua oficial. Neste período, nenhum sistema linguístico estava banido da educação dos surdos, eles, os professores, podiam utilizar qualquer meio de transmissão dos conhecimentos, sem dar ênfaseou omissão a qualquer língua.

Dentro dessa metodologia mista de ensino, existiam duas abordagens de ensino, em que havia a concomitância no ensino da língua de sinais e da língua oral. A principal dificuldade encontrada nesse processo, estava centrado nas diferenças gramaticais dentro de cada língua. A primeira abordagem diz respeito ao desenvolvimento da criança surda em L1 para, posteriormente, adquirir a L2; a segunda, propunha um ensino com dupla apreciação das línguas, tanto oral quanto a de sinais. Nesta segunda, o ensino da língua materna dos surdos, desrespeitava toda a gramática intrínseca aos seu sistema linguístico. De acordo com Ciccone (1996, p. 6-7) a comunicação total é

uma filosofia de trabalho voltada para o atendimento e a educação de pessoas surdas. Não é, tão somente, mais um método na área e seria realmente, um equívoco considerá-la, inicialmente, como tal (...). A Comunicação Total, entretanto, não é uma filosofia educacional que se preocupa com ideais paternalistas. O que ela postula, isto sim, é uma valorização de abordagens alternativas, que possam permitir ao surdo ser alguém, com quem se possa trocar idéias, sentimentos, informações, desde sua mais tenra idade. Condições estas que permitam aos seus familiares (ouvintes, na grande maioria das vezes) e às escolas especializadas, as possibilidades de, verdadeiramente, liberarem as ofertas de chances reais para um seu desenvolvimento harmônico. Condições, portanto, para que lhe sejam 
franqueadas mais justas oportunidades, de modo que possa ele, por si mesmo lutar em busca de espaços sociais a que, inquestionavelmente, tem direito.

Assim, a comunicação total não se contrapõe à filosofia oralista, que até então estava fortemente enraizada nas escolas de educação dos surdos, ela surge como uma metodologia complementar, que servia de subsídio para a aquisição da fala. Ela não era somente um método estruturado, mas tinha uma outra visão sobre a aquisição de L2 por crianças surdas. Os problemas envolvendo a filosofia oralista e a comunicação total estão atrelados aos aspectos de construção da identidade de um sujeito estereotipado ou esculpido pelos anseios dos ouvintes, que idealizavam como que eles deveriam aprender uma língua estrangeira. Desse modo, a comunicação total também não surtiu efeitos, tendo em vista a sua abordagem de ensino multifacetado, em que objetivava usar a sinalização apenas como mecanismo de aquisição da oralidade.

\subsection{O bilinguísmo}

Por último, temos a filosofia bilíngue, ou despertamento cultural, que teve início na década de 60 e resultou em um método de ensino mais apropriado aos surdos. A Suécia foi um dos primeiros países a adotar o bilinguismo como forma, modelo de ensino, tendo seu sistema de sinais reconhecido como língua oficial dos surdos no ano de 1981. Com o reconhecimento da língua de sinais como língua oficial de comunicação dos surdos, no ano de 1983, foi introduzido naquele país um novo modelo de currículo escolar, que dava primazia à educação bilíngue nas escolas de surdos, postulando que seus professores tivessem domínio da língua de sinais. O bilinguísmo no Brasil consiste na inserção das duas línguas aos alunos surdos: a língua portuguesa como L2 e a língua brasileira de sinais como L1.

No Brasil, a Libras foi oficializada em 24 de abril de 2002 pela Lei Federal $n^{\circ} 10.436$, após grande empenho e reivindicações da comunidade surda por uma educação bilíngue, em que a língua materna fosse ofertada como L1 e a língua portuguesa como L2. Salles et al. (2004) afirma que a educação bilíngue é uma metodologia de ensino embrionária, e é uma proposta que preconiza o ensino das duas línguas no contexto escolar de aprendizagem. Assim como na filosofia da comunicação total, no bilinguismo também há duas vertentes no que tange ao ensino. Uma defende que a criança surda deve aprender primeiro a língua de sinais, logo após, deve ser letrada na língua oficial majoritária do seu país. 
A segunda vertente de ensino, postula que a criança surda deve aprender primeiro a sua língua materna, e, posteriormente, apenas a modalidade escrita da língua portuguesa. Nesse caso, exclui-se a língua oral. Botelho (2013), defende que não há como o surdo aprender outra língua sem que antes seja letrado e alfabetizado em sua língua materna. A língua escrita e a oral são ensinadas como línguas estrangeiras (L2) na educação bilíngue, sendo dependentes da aquisição primária da língua de sinais. Nesta perspectiva, o bilinguísmo, segundo Lacerda (1998, p.10), se contrapõe

[...] ao modelo oralista porque considera o canal viso gestual de fundamental importância para a aquisição de linguagem da pessoa surda. E contrapõe-se à comunicação total porque defende um espaço efetivo para a língua de sinais no trabalho educacional; por isso advoga que cada uma das línguas apresentadas ao surdo mantenha suas características próprias e que não se 'misture' uma com a outra.

Lacerda (1998) discorre sobre o fato de que a exposição do aluno surdo, primeiramente, se dá com a língua oral, dentro de casa e em diversos ambientes, o que pode acarretar problemas de aquisição da Libras e dificuldades de comunicação, por isso é importante que a família esteja atenta busque inserir o surdo em uma comunidade linguística. Lacerda ainda defende que os preceitos da Libras e do português devem ser ensinados de acordo com o seu sistema de regras próprias, pois cada língua possui suas particularidades, tornando-se, assim, impossível falar as duas línguas ao mesmo tempo.

Segundo Quadros e Karnopp (2004), os estudos acerca dessa última filosofia tem mostrado resultados satisfatórios no campo educacional, tendo como ponto de partida a língua natural e ponto, talvez final, a língua escrita. De acordo com Santana (2007, p. 166), o bilinguismo inaugura um novo debate na área da surdez, pois,

[...] defende a primazia da língua de sinais sobre a língua portuguesa, antes aprendida simultaneamente na comunicação total, ou isoladamente no oralismo. Essa primazia, defendida por muitos autores tem por base dois argumentos. Primeiro, a presença de um período crucial para a aquisição da linguagem. Segundo, a existência de uma competência inata, na qual para aprender uma língua, bastaria estar imerso em comunidade linguística e receber dela inputs linguísticos cruciais.

Após ser oficializada no Brasil, três anos depois, em 2005, os currículos universitários começaram a sofrer alterações. O decreto 5626/2005, que regulamenta a Lei 10.436/2002 em 
seu artigo $3^{\circ}$, informa sobre a inserção da Libras como disciplina curricular obrigatória nos cursos de formação de professores para a educação básica (BRASIL, 2005). Para concluir, é importante lembrarmos de que só conseguiremos estruturar, adquirir e sistematizar a nossa língua, seja ela oral ou de sinais, a partir da interação com outro sujeito dotado das mesmas habilidades. São habilidades que se desenvolvem de geração a geração, em que um sujeito ensina e outro aprende, ou ainda, os dois ensinam ao mesmo tempo (SACKS, 1989).

\section{5 . Breve histórico da educação de surdos no Brasil}

Este tópico objetiva, de forma holística, mostrar a realidade da educação dos alunos surdos no Brasil. Como somos sabedores, a educação de alunos com surdez passou por três fases durante o processo histórico de ensino. Cada um desses processos, ou filosofias, estavam vinculados aos desejos políticos, ou seja, a educação era rotulada de acordo com o pensamento dominante.

Diante disso, vamos rememorar cada uma dessas filosofias e seus preceitos. A primeira, à qual fizemos referência neste estudo, foi o oralismo, que pregava a fala como princípio de comunicação para os surdos. Nesse período, gestos e sinais foram banidos das escolas. Logo depois emergiu a comunicação total, que aniquilava alguns pressupostos postulados pela primeira filosofia e que dava abertura para o uso dos sinais, mas somente como ponte para a aquisição da língua oral. Em seguida, o bilinguismo teve a sua epifania, que não corroborou com as finalidades apregoadas pelas primeiras concepções filosóficas de ensino e que permanece até os dias de hoje como metodologia ou filosofia que tem surtido efeito na educação dos estudantes surdos.

Em junho de 1855, Ernest Huest apresentou ao então Imperador D. Pedro II, um relatório, cujo objetivo era o de defender a construção de um estabelecimento voltado para as pessoas surdas (VAGULA, 2014). Acatado o projeto de criação do instituto, teve início as suas atividades em $1^{\circ}$ de janeiro de 1856 , de forma particular. O programa de ensino englobava várias áreas, desde a língua portuguesa, estudos matemáticos, históricos, geográficos e outras disciplinas voltadas para o comércio e escrituração mercantil. 


\subsection{Letrado ou alfabetizado? Limpando a poeira das velhas concepções.}

Quando o assunto é saber se crianças surdas são alfabetizadas ou letradas no contexto escolar, há uma divergência de opiniões de autores que se dedicam a esse assunto. Alguns acreditam que a alfabetização não atende às necessidades de aprendizagem dos alunos surdos, e consideram o letramento como a melhor forma de ensinar L1 e L2. Outros teóricos discordam desse pensamento e afirmam que as escolas não são capazes, ainda, de tornar um estudante surdo um indivíduo letrado, como Botelho (2013, p. 65), que afirma:

No caso dos surdos, os processos de escolarização não estão voltados para a construção de sujeitos letrados. E como problema adicional, as escolas de surdos desconsideram que aprender a fazer o uso competente, constante e hábil de Leitura e de escrita, é inteiramente dependente da aquisição de uma língua, a língua de sinais, e de linguagem.

Eis o nó que precisa ser desatado dentro das escolas. A necessidade de limpar a poeira das velhas concepções de ensino, que não dão mais de conta das reais necessidades da educação é urgente, principalmente no ensino bilíngue. Não há como se construir um sujeito que domine plenamente a comunicação, sem que antes ocorra a construção de uma identidade, da língua e da linguagem. Desta forma, não há como torna-se um sujeito letrado sem conhecer as convenções da própria língua, embora possam existir sujeitos letrados que não foram alfabetizados na educação formal. Por exemplo: se um senhor de certa idade, que nunca foi à escola, nem aprendeu o alfabeto, precisa atravessar a rua e percebe que semáforo esta vermelho para pedestres, é claro que ele não vai cruzar a rua até que a passagem de pedestres seja liberada, ou seja, até que o sinal luminoso mostre a cor verde. Sabemos que este senhor desconhece o código, mas reconhece as sinalizações de permissão e proibição, isso também é um letramento.

Lima; Lima; Souza (2014), vão além da concepção de "ser letrado" ou "ser alfabetizado". De acordo com as autoras, os problemas relacionados à aquisição do código e seu uso em situações reais de comunicação, podem estar relacionados ao próprio ambiente familiar. Alunos surdos, filhos de pais surdos, têm mais facilidade na alfabetização que alunos surdos filhos de pais ouvintes, tendo em vista o contato rotineiro com a língua e o desenvolvimento mais célere de habilidades. Ainda nesta linha de raciocínio, as autoras ressaltam a importância de alfabetizar letrando, o que poderá despertar interesse por parte do aluno para a aquisição de uma segunda língua: 
[...] a alfabetização e o letramento são muito importantes, tanto para o desenvolvimento dos alunos surdos quanto para os ouvintes, por isso não se deve acomodar na possibilidade de melhorar esse quadro, cabendo sempre aos docentes e discentes melhor preparar e capacitar-se ao máximo a fim de que se possam superar todos os obstáculos para o ensino da alfabetização e letramento nos alunos surdos (LIMA; LIMA; SOUZA, 2014, p. 163)

Os processos de alfabetização dos alunos surdos devem ser contextualizados, no sentido de que a criança só aprenderá determinado sinal se ela, primeiro, visualizar a imagem, atribuirlhe significado e, em seguida, fazer a leitura do código, ou seja, ler o nome do objeto em língua portuguesa. Assim, a criança vai assimilando a figura, o sinal e sua escrita em L2. Vale lembrar que nem todos os alunos vão aprender de igual forma, ou com a mesma intensidade. Isso não quer dizer que eles são incapazes ou limitados, apenas demonstra a necessidade da inserção de outros métodos que desenvolvam a aprendizagem de forma mais significativa.

De acordo com Lima; Lima; Souza (2014), os alunos surdos no ambiente escolar são e devem ser alfabetizados e letrados na perspectiva do letramento visual, levando em conta a importância de agregar a função da alfabetização ao papel social transformador que tem o letramento na vida escolar de uma criança. De modo igual, as pesquisadoras admitem que não são apenas os alunos surdos que devem trilhar este percurso. Os ouvintes também necessitam de uma ambientação que lhes proporcione uma articulação entre a vida escolar e a vida social.

De acordo com Baldo e Iacono (2008), não podemos falar em alfabetização de surdo sem pensar nas práticas de letramentos presentes nas relações sociais do estudantes, no contexto familiar, na rua, com os amigos, na padaria e em diversos ambientes, é por meio dessas relações que ele conhece e se apropriar da escrita da língua portuguesa como sua segunda língua, para utilizá-la de forma competente nas suas relações cotidianas. Acreditamos que essa forma seria o letramento. Por outro lado, é importante lembrarmos que a alfabetização também exerce papel importante nesse cenário. No contexto de aquisição de uma segunda língua, é necessário a aquisição também do sistema de escrita, especialmente no que diz respeito ao ensino de LP para alunos surdos.

\subsection{Os professores e os intérpretes - as observações}

Nesta seção resguardaremos a identidade dos sujeitos que participaram da pesquisa e que são professores atuando diretamente com os alunos surdos. Utilizaremos o código P1 para fazer referência ao professor do $6^{\circ}$ ano e P2 para o $7^{\circ}$. Nas observações em diário de campo, 
realizadas na Escola de Cidadania José Freire Filho no município de Crateús (CE), quando acompanhamos as aulas de LP $\operatorname{dos} 6^{\circ}$ e $7^{\circ}$ anos de dois professores de língua portuguesa, acompanhados de dois intérpretes, foi possível perceber, na sala do sexto ano, onde o P1 atua, uma prática pedagógica que não corrobora os preceitos da filosofia bilíngue. O P1 trabalha de forma incansável com o livro didático, o único suporte imagético que contribui, embora não muito, para o esclarecimento do aluno surdo. A metodologia de ensino não leva em consideração as especificidades desse aluno. Enfatizamos que o professor não tem formação em Libras e é a primeira vez que trabalha com alunos surdos nesta escola. Quase sempre, fica a cargo do intérprete fazer a relação entre língua oral, escrita e de sinais. Todos os procedimentos realizados pelo P1 são feitos de forma oral e não há a presença de sinalizações ou imagens ou contato direto com o aluno surdo. Seu planejamento, evidentemente, não inclui o estudante surdo como sujeito, nem prioriza, mesmo que de forma superficial, a língua materna desse discente.

Nas observações das aulas do P2, que atua na sala do $7^{\circ}$ ano, foi possível perceber um maior rendimento em relação à aprendizagem do aluno, mas também foi notório o não engajamento e a ausência de preocupação do professor em relação ao aluno surdo. Da mesma forma, o P2 não utiliza mecanismos que ajudem o aluno a entender os assuntos abordados, como mencionamos anteriormente. O livro didático é o único recurso visual disponível para o discente. Assim como o P1, o P2 também não tem formação na área para atuar com alunos surdos, passando toda a responsabilidade de aprendizagem de seu aluno para o seu intérprete. Nessa sala, podemos encontrar um estudante mais atento às atividades e que acompanha a turma, reconhece em língua de sinais e em língua portuguesa os números e letras e quando sente dificuldades faz perguntas.

As observações realizadas em sala, também tiveram como escopo o intérprete como um dos mediadores do processo de ensino e aprendizagem, no que tange o ensino de língua portuguesa para os alunos surdos. Essa etapa consistiu em extrair dos intérpretes, através de conversa informal, dificuldades e situações que ponham em cheque a aprendizagem desse aluno e problemas relacionados à aprendizagem de L2 por parte dos discentes. Cada aluno é acompanhado por um intérprete, em todos os componentes curriculares, durante o turno em que está regularmente matriculado. O acompanhamento pelo intérprete é algo bastante profícuo para o desenvolvimento da aprendizagem do discente com surdez. O papel do intérprete é, de 
fato, socializar as atividades, mediar as discussões acerca dos conteúdos curriculares com o aluno surdo e inseri-los no contexto escolar e nas práticas sociais de interação. Mas quando o assunto são as dificuldades no contexto de ensino, o discurso dos intérpretes bebe na mesma fonte do discurso do professor. Para eles, as principais dificuldades advêm do material ofertado pelo sistema de ensino, o que não condiz com as necessidades de aprendizagem de um aluno surdo, pois, o livro didático não comunga com os pressupostos basilares para a educação bilíngue. Sousa (2015) nos diz que a língua brasileira de sinais foi desenvolvida no Brasil pelos surdos como forma de comunicação entre eles, tendo com uma estrutura gramatical própria, diferente das línguas orais, pois sua modalidade é a gestual-visual. Por isso a necessidade de adaptações curriculares, com um material didático que favoreça a aprendizagem deste aluno.

\section{Conclusão}

Após algumas leituras sobre o ensino de língua portuguesa para alunos surdos, concluímos que este estudo é mais um tangente que irá contribuir na educação de surdos, no sentido de que temos que lutar fortemente para darmos nova roupagem ao ensino bilíngue, que está se formatando monolíngue em nossa realidade nas escolas brasileiras. Discutimos, nesta pesquisa, a alfabetização e o letramento como agenciadores da educação dos surdos, especialmente em segunda língua, mas isso não se reproduz na sala de aula, quando constatamos em nossa pesquisa que alunos ouvintes de $6^{\circ}$ e $7^{\circ}$ anos já possuem domínio da leitura e da escrita, enquanto os surdos, numa leitura fácil com palavras conhecidas e textos curtos, acabam se perdendo e a língua portuguesa na modalidade escrita acaba se tornando um empecilho no desenvolvimento da leitura.

Nesse sentido, entendemos o ensino de LP com base no letramento, como sendo as práticas sociais de uso da linguagem, e que abordem as diversas condições de leitura, produção e entendimento de um texto ou imagem. Essa prática de expor os alunos surdos à LP com mais ênfase do que à Libras é bastante corriqueira, a começar do próprio livro didático, impróprio às especificidades de aprendizagem do surdo que não são levadas em consideração quando o assunto é educação bilíngue.

Portanto, concluímos que os alunos observados não acompanham as turmas em que estão inseridos, as dificuldades de leitura e escrita são as principais problemáticas presentes. Neste sentido, percebemos que os alunos surdos, não são inseridos em prática sociais de 
letramento e nem são alfabetizados, pois não dominam o sistema linguístico da Libras e nem da LP.

As aulas não são planejadas levando em conta as especificidades do aluno, não há inclusão no sentido de material de estudo adequado, e o espaço da sala de aula não contribui para tal. Em todos os cartazes que foram produzidos durante as observações e no espaço externo à sala de aula, havia a prevalência da língua majoritária e nada com relação à Libras. Assim, o ensino de língua portuguesa mostrou-se deficiente quanto a formar o discente surdo para exercer o mesmo papel social que os ouvintes. Por conseguinte, percebemos que os alunos surdos não têm elevado nível de letramento em LP.

Neste contexto, faz-se necessário um trabalho efetivo com base nos gêneros textuais, aqueles mais rotineiros no dia a dia desses alunos. Podemos citar, por exemplo, a receita de um bolo ou a agenda escolar. A receita de bolo pode ser trabalhada com a exploração do léxico, com o discernimento das relações existentes entre colher de açúcar e colher de sopa de açúcar, colher de chá e colher de chá de cacau em pó, por exemplo. Quanto à agenda escolar, o professor poderá explorar as datas comemorativas de cada mês. No caso de agenda doada pela própria escola, na maioria das vezes, cada mês expõe uma figura importante do município. Tomando isso como base, o professor poderá mergulhar no histórico desses personagens, abordando sua importância para a sociedade. Vale lembrar a importância de empreender um estudo sobre as funcionalidades sociais desses gêneros textuais, sua estrutura e suportes. Tendo em vista que o ensino de língua portuguesa aos alunos surdos deve ter texto, imagem e sinalização, o intérprete deverá ser o sujeito mediador desses conhecimentos. Por isso a necessidade de formação específica para a docência e sua participação nas atividades de planejamento voltadas somente para alunos surdos. As limitações da pesquisa deixaram muitas questões sem respostas mais consistentes, porém isso nos incentiva a seguir buscando entender vários pontos que permeiam o ensino de LP para surdos e afirmamos que este estudo não finda por aqui, a pretensão é alçar voos maiores em prol de uma educação bilíngue, pública e de qualidade às pessoas surdas.

\footnotetext{
Abstract

This article aims to understand how the teaching of the Portuguese Language (LP) to deaf students happens and if said students are imbued with social practices of literacy. For this end, a research with a qualitative approach and a case study were carried out, in which the work was consolidated through observations at the José Freire Filho school - Crateús - CE in the inclusive rooms researched at this school. This study was based on the writings of Soares, Kleiman, Botelho, Fernandes, and others, to expose that deaf students are not literate in sign language
} 
and, even though they do not know their natural language, they are exposed to the teaching of Portuguese. At the end of this work, there one can realize the need for a reform in the education of deaf students, with a view to reviewing methodological teaching practices and offering, in an isonomic way, a teaching based on students' specificities.

Keywords: Literacy. Libras. Portuguese language. Teaching.

\section{Referências}

ALBRES, Neiva de Aquino. Intérprete de Língua de Sinais: um olhar sobre as particularidades dentro do contexto educacional. GT10 - processo de ensino e aprendizagem e educação especial. ENCONTRO DOS CURSOS DE PÓS-GRADUAÇÃO LATO-SENSU DA REGIÃO CENTRO OESTE, Campo Grande - MS, 2003.

BALDO, Cirlei Fátima; IACONO, Jane Peruzo. Letramento para alunos surdos através de textos sociais. PDE - Programa de Desenvolvimento da Educação, 2008.

BRASIL. Lei de Diretrizes e Bases da Educação Nacional. Lei número 9394, 20 de dezembro de 1996.

Decreto $n^{\circ}$ 5.626, de 22 de dezembro de 2005, regulamenta a Lei $n^{\circ} 10.436$, de 24 de abril de 2002, que dispõe sobre a Língua BrasiLeira de Sinais - Libras, e o art.18 da Lei n ${ }^{\circ}$ 10.098, de 19 de Dezembro de 2000.

Lei $\mathbf{n}^{0} 10.436$ de 24 de abril de 2002. Dispõe sobre a Língua BrasiLeira de Sinais (Libras) e dá outras providencias.Brasília: Presidencia da Republica, Casa Civil, 2002.

BRITO, Rafaela da Silva. O professor e o processo de alfabetização do aluno surdo. Caicó: UFRN, 2015.

BOTELHO, Paula. Linguagem e Letramento na Educação dos Surdos - Ideologias e Práticas Pedagógicas. 3. ed. Belo Horizonte: Autêntica, 2013.

CAPOVILLA, A. G. S., \& CAPOVILLA, F. C. Alfabetização: método fônico. São Paulo, SP: Memnon, Fapesp-CNPq, 2002.

CARVALHO, Marlene. Alfabetizar e letrar: um diálogo entre a teoria e a prática. 7. ed. Petrópolis, RJ: Vozes, 2010.

CICCONE, Marta. Comunicação total: introdução, estratégias a pessoa surda. $2^{\mathrm{a}} \mathrm{ed}$. Rio de Janeiro: Cultura Médica, 1996.

DORZIAT, Ana. Concepções de Surdez e de Escola: ponto de partida para um pensar pedagógico em uma escola pública para surdos. São Carlos / SP: Trabalho de Tese (Doutorado), UFSCar (mimeo.), 1997. 
FERNANDES, Sueli de Fátima. Educação bilíngue para surdos: identidades, diferenças, contradições e mistérios. Curitiba, 2003, Tese (Doutorado em Letras), Universidade Federal do Paraná.

FERNANDES, S. Letramentos na educação bilíngüe para surdos. In: BERBERIAN, A. P.; MASSI, Giselle; ANGELIS, C. M. de, (org.) Letramento: referenciais em saúde e educação. São Paulo: Plexos, 2006.

FERREIRO, Emília. TEBEROSKY, Ana. Psicogênese da Língua Escrita. Trad. Diana Myrian Lichtenstein et all. Ed. Artmed, Porto Alegre, 1999.

GOLDIFELD, Marcia. A criança surda: linguagem e cognição numa perspectiva sóciointeracionista. 2 ed. São Paulo: Plexus, 2002.

KLEIMAN, Angela B. Os significados do letramento: uma nova perspectiva sobre a prática social da escrita. Campinas, SP: Mercado das Letras, 1995

LACERDA, Cristina Broglia Feitosa de. Um pouco da história das diferentes abordagens na educação de surdos. Caderno Cedes, vol. 19, n 46. Campinas, 1998.

LIMA, Marisa Dias. Alfabetização e letramento com uso da LIBRAS nas crianças surdas. Revista Perquirere, 11(1): 144-165, jul. 2014.

LIMA,Marisa D. A importância da LIBRAS na escolarização dos surdos. Trabalho de Conclusão de Curso (Pedagogia) - Centro Universitário de Patos de Minas, Patos de Minas, 2007.

LILLO-MARTIN, D. C. Universal Grammar and American Sign Language: Setting the Null Argument Parameters. Kluwer Academic Publishers. 1998.

MONTEIRO, Myrna Salerno. ETD. Educação Temática Digital. Campinas, v.7, n2, p. 292-302, jun. 2006.

PEREIRA, Maria Cristina Costa.(org) Orientações Curriculares e Proposição de Expectativas de Aprendizagem para a Educação Infantil e Ensino Fundamental. São Paulo: Secretaria da Educação do Estado de São Paulo, 2008.

PEREIRA, Maria Cristina Costa. O ensino de português como segunda língua para surdos: princípiosteóricos e metodológicos. Educar em Revista, Curitiba, Brasil, Edição Especial n. 2/2014, p. 143-157. Editora UFPR.

QUADROS, Ronice Muller de. O bi do bilinguísmo na educação de surdos In: Surdez e bilingüismo.1 ed.Porto Alegre : Editora Mediação, 2005, v.1, p. 26-36.

QUADROS, Ronice Muller de; KARNOPP, L. B. Língua de Sinais Brasileira: estudos linguísticos. $1^{\mathrm{a}}$ ed. Porto Alegre: Artmed, 2004.

SÁ, Nídia Regina Lima. Cultura, Poder e educação de Surdos. Manaus: Universidade Federal do Amazonas, 2002. 
SACKS, Oliver. Vendo vozes: uma viagem ao mundo dos surdos. Tradução: Laura Teixeira Motta. Editora. Schwracz Ltda. São Paulo, 1989.

SALLES, Heloísa Maria Moreira Lima [et al]. Ensino de língua portuguesa para surdos: caminhos para a prática pedagógica. Brasília: MEC, SEESP, 2004. $2^{\circ}$ v.: il. (Programa Nacional de Apoio à Educação dos Surdos).

SANTANA. Ana Paula. Surdez e Linguagem: aspectos e implicações neurolinguisticas. São Paulo, Plexus, 2007.

SOARES, Magda. Letramento: um tema em três gêneros. 2ed. Belo Horizonte, Autêntica, 2006.

SOARES, Magda. Letramento: um tema em três gêneros. $3^{\text {a }}$ ed. 4 reimp. - Belo Horizonte: Autêntica Editora, 2017.

SOUSA, Viviane. A importância do papel do intérprete de libras no processo de aprendizagem do aluno surdo em sala de aula nas escolas de ensino comuns. Cadernos da Fucamp, v.14, n.20, p.168-181/2015.

SVARTHOLM, K. Como leerles a los sordos? Disponível em: www.sitiodesordos.com.ar>. 2003. Acesso em: 18/07/2018.

SOUZA, Deusivânia Laiana Alves de; LIMA, Marisa Dias; LIMA, Márcia Dias. Alfabetização e Letramento com o uso da LIBRAS nas crianças surdas. Revista Perquirere, 11(1): 144165, jul. 2014.

VAGULA, Edilaine; MALZINOTI, Sandra Cristina. Educação Inclusiva e Língua Brasileira de Sinais. Londrina: UNOPAR, 2014.

VAL, Maria G. C. O que é ser alfabetizado e letrado? In: CARVALHO, Maria A. F. \& MENDONÇA, Rosa H. (org.). Práticas de leitura e escrita. Brasília: Ministério da Educação, 2006. p. 13-17. 